Ng'ambi, D. \& Bozalek, V. (2013). Leveraging informal leadership in higher education institutions: A case of diffusion of emerging technologies in a southern context. British Journal of Educational Technology, 44 (6): 940-950

\title{
Leveraging informal leadership in higher education institutions: A case of diffusion of emerging technologies in a southern context
}

\author{
Dick Ng'ambi and Vivienne Bozalek
}

\begin{abstract}
In the last decade, emerging technologies and transformative practices have diffused into higher education social systems in ways that formal leadership styles are increasingly stretched to both keep abreast of and to manage. While many scholars have argued for the importance of the role of leadership styles in shaping the strategic direction of institutions, there is a paucity of research on the role that informal leaders, and more particularly opinion leaders and change agents, can play in enabling wide-scale adoption of innovations in higher education institutions. This paper focuses on the ways in which leadership in higher education can best extend their influence to accelerate the diffusion of transformational educational practices using emerging technologies by leveraging informal leaders. To illustrate how this could be achieved, we report on a study of 22 public higher education institutions in South Africa involving 259 participants who responded to an online survey. The survey focused on the uses of emerging technologies to transform the teaching and learning practices and the nature of institutional support such initiatives received. The findings reveal that for emerging technologies to be diffused in institutional social systems, more transformative and less transactional leadership is required. The paper proposes a model for accelerating the diffusion of emerging technologies in higher education institutions and concludes that leveraging informal leadership is particularly critical in accelerating the uptake of emerging technologies practices.
\end{abstract}

\section{Introduction}

In our editorial in the July British Journal of Educational Technology special issue on emerging technologies and changing learning/teaching practices, we outlined 12 areas that will define educational technology research in the next 5 years, one of which is understanding institution-wide adoption and use of emerging technologies in higher education (Ng'ambi \& Bozalek, 2013). This paper contributes to this area of concern with a specific focus on how formal leaders (ie, usually senior academics not officially in senior management positions) can leverage informal leadership to achieve institutional-wide adoption of emerging technologies for transforming the teaching and learning practices. 
Formal leaders of Higher Education Institutions (HEIs) who are in senior management positions are required to steer their educational institutions through the complexity of changing global 21st century contexts (Casas \& Stojanovic, 2013).

\section{Practitioner Notes}

What is already known about this topic

1. Higher Education Institutions (HEIs) globally and particularly in Africa are facing increasing pressure from both internal (alignment of teaching and learning, strategic plans, pressures from student expectations) and external sources (quality assurance bodies, professional bodies, higher education national bodies and graduate employers) to improve their pedagogical practices.

2. Emerging technologies are impacting on the practices of higher education, but these practices are isolated and universities tend to underutilise their potential leadership role in shaping institution-wide pedagogical changes.

3. Leaders of HEIs are mostly reactive in dealing with challenges impacting their institutions and are slow at producing proactive strategies to address these challenges. What this paper adds

4. HEIs have "pockets of innovation" (Vogel, 2010, p. 42) that can be harnessed for institution-wide uptake.

5. Informal leaders (opinion leaders) are a new wave of leadership that formal higher education leaders need to exploit to ensure wide adoption of innovative practices.

6. Grounded in a study of HEIs in South Africa, we propose a model for accelerating and effectively managing the diffusion of emerging technologies in higher education.

Implications for practice and/or policy

7. The formulation of conditions in which opinion leaders' advocacy roles can flourish to the benefit of institutions.

8. Legitimisation through acknowledgement of the work of pockets of innovators.

9. Leveraging participatory approaches (inclusive of both change agents and opinion leaders) to formulate new policies.

The Technology Outlook for UK Tertiary Education 2011-2016 Report by the New Media Consortium and Joint Information Systems Committee supports centres in the UK, rightly observes that the Internet has profoundly impacted the teaching and learning practices in higher education (Johnson \& Adams, 2011), yet management response has not kept pace with this (Bates \& Sangrà, 2011; Vogel, 2010). Distinguishing between the 20th and 21st century changes in teaching methods, Bassendowski and Petrucka (2013) advance a theory of pull-push to distinguish between education systems of the two centuries. ". . . [I]n the late 1920s, very few resources existed and the teaching methods consisted largely of lectures, occasional case studies and some problem solving situations. Students were passive learners who focused on note taking, memorization and the ability to sit quietly in the lectures. They were generally overwhelmed with the amount of factual knowledge that was pushed upon them and often dropped behind in note-taking" (Bassendowski \& Petrucka, 2013, p. 665). We infer from Bassendowski and Petrucka (2013) that the education system in the 2oth century was predominantly characterised by how 
much information could be pushed to students, while in the 21st century, students' synthesis of information pulled from both a deluge of electronic resources and social networks is what is defining the educational practices. The pull-push metaphor can be extended to leadership styles in that push represents top-down and pull a bottom-up leadership style. Our view is that as emerging technologies transform practices of relatively few practitioners, the role of leadership is to identify innovative practices and devise strategies to ensure institutional uptake of such innovations, in this way leveraging informal leaders to drive institutional change, thus achieving a bottomup/top-down leadership approach.

The paper is organised as follows: we define emerging technologies, after which webriefly describe leadership in context of emerging practices, the southern context, leadership concerns and areas of influence. We outline Rogers' (2003) diffusion of innovation theory, which we use as a theoretical lens to make our argument. We then discuss the methodology, data analysis, discussion and conclusion referring to our South African case study.

\section{Emerging technologies}

We define emerging technologies in the way in which George Veletsianos (2010, p. 17) has chosen to identify them-as "tools, technologies, innovations, and advancements utilized in diverse educational settings to serve varied educationrelated purposes." This definition is helpful for us in South Africa in that it focuses on the diversity of tools and practices that may be regarded as emerging in our context, which may be different from the technologies or practices in northern contexts and those identified in the annual Horizon reports (Johnson et al, 2013).

\section{Leadership in context of emerging practices}

One of the challenges of investigating the role of leadership in ensuring uptake of emerging technologies for transforming pedagogical practices is that "leadership" as a concept has no universally accepted definition. Siewiorek, Gegenfurtner, Lainema, Saarinen and Lehtinen (2013) describe leadership as "persuading people to set aside, for a time, their individual concerns and pursuits and work in support of the communal interest" (p. 3). This definition explains the conundrum of leadership in higher education. There are as many concerns and pursuits in higher education as there are actors and stakeholders. One of the leadership challenges is finding an appropriate approach to leverage individual concerns in pursuit of a communal interest. These concerns regarding leadership led us to ask the following question that informs this paper: how could HEI leadership best use its influence to persuade its actors to set aside concerns to adopt the use of emerging technologies in the quest to align institutions with a communal interest of transforming education practices with these tools?

Randall and Coakley (2007) distinguish between two types of leadership models: transactional and transformative leadership. Under transactional leadership, people perform in exchange of a reward, whereas transformative leadership "is the ability to motivate employees to excel beyond what is expected through the use of individual consideration, intellectual stimulation, and charisma" (p. 327). In addition to transactional and transformative leadership styles, Siewiorek et al (2013) add heroic 
and post-heroic leadership styles. "Heroic leadership is characterised by omnipotence, rightness and codependency as the main characteristics of a leader. Post-heroic leadership refers to empowerment of members, risk taking and the development of members" (p. 4). Marshall (2007) also makes reference to the need in the 21st century to shift from "heroic" leadership to dispersed leadership happening at all levels of the HEI for sustainable transformation, which is not a one-off event, to take place.

\section{Southern context}

This research takes place in a southern context where technologies and associated practices, which are emerging, may be quite different from the northern contexts. Although the Horizon reports (Johnson et al, 2013) serve as useful dashboards for teaching and learning on the higher education terrain, they tend not to be cognisant of the sociocultural settings that influence appropriation of technologies in varying contexts.

However, even in southern contexts, emerging technologies can be seen as empowering both educators and students to engage in practices that are less dependent on institutions' infrastructure, and leadership of HEIs has tended to be slow in exerting leadership to harness these opportunities. There are many innovative practices initiated by individual academics and students that exploit the affordances of emerging technologies, but these practices are confined to the small domain of these individuals and at most to their departments. It is against this background that we wondered about the style of leadership that would enable institution-wide adoption of these innovative practices. As a point of departure, we reviewed literature on leadership concerns and areas of influence.

\section{Leadership concerns and areas of influence}

Regardless of the leadership context, responding to crises (Goldman, 2012) and exerting influence (Martin \& Marion, 2005) are two of the leaders' functions, among others. The concerns that arise from these leadership functions in higher education are classified into three issues: allocation of scarce resources, clarifying roles and responsibilities, and maximising communication (Flumerfelt \& Banachowski, 2011). Flumerfelt and Banachowski argue that when faced with any concern, one of the three issues becomes critical. For example, a concern that arises from economic pressures might make the allocation of scarce resources to become critical. The critical events become crises when left unsolved. Our thesis is that the uptake of emerging technologies is a leadership concern, which risks becoming a crisis if innovations are left unrecognised or unsupported.

\section{Diffusion of innovation theory}

The diffusion of innovation theory developed and refined by Rogers (2003) provides a useful framework to understand how both global and local innovations diffuse and infuse into social system and how such diffusion/infusion could be managed to ensure quick uptake of higher education. Rogers and Scott (1997) define a social system (ie, constituting individuals, informal groups, and/or subsystems) as a set of interrelated units working together to achieve a common objective, and it is through it (social system) that innovation diffuses. Rogers (2003, p. 27) sees diffusion as a social process of change, where innovation 
or new ideas are created and shared in both spontaneous and planned ways, through channels of communication among members of a social system with the view to create mutual understandings and consequently change the system over a period of time. Rogers and Scott (1997) outline the process of diffusion as involving four stages:

(1) an innovation (2) is communicated through certain channels (3) over time (4) among the members of a social system. According to Rogers and Scott (ibid.) opinion leaders are multipliers who use both mass media and interpersonal channels to ensure innovations reach a critical mass ie, when enough individuals in a social system adopt an innovation and that is when the practice becomes self-sustaining. The emerging technologies such as blogs, Facebook, Wiki and Twitter are some of the communication channels at the disposal of opinion leaders.

The ability of an individual, such as the academics we studied, to either be innovative or act as opinion leaders depends according to Rogers (2003) both on the individual's characteristics and the established behaviour patterns for members of the system. Rogers and Scott (1997) remind us that norms are the established behaviour patterns for the members of a social system. It is in the changing of these norms and behaviour patterns for members that the role of formal leadership is implicated. For change to occur, innovative educators need opinion leaders who are regarded as influential on people's attitudes and behaviour in the system, whether they are formal or informal leaders, innovative or conservative. Change agents in teaching and learning in the higher education sector could be seen as those involved in professional development. With regard to innovations or new ideas, Rogers (2003) describes five categories-innovators, early adopters, early majority, late adopters and laggards. These categories provide a way of understanding that diffusion of innovation in HEI is not uniform, but the goal is to ensure that through the channels of communication, adoption is accelerated through the different categories.

An example of the role of opinion leaders in the diffusion of an innovation in HEI is well exemplified in the following: In 2013, the Apereo Foundation's Teaching With Sakai Innovation Award (TWSIA) (http://openedpractices.org/twsia) recognised two change agents from South Africa, Prof Cheryl Hodgkinson-Williams and Dr Cheryl Brown, for their innovative pedagogy in an Advanced Research Design course. The TWSIA award seeks to recognise educational applications of Sakai (http://www.sakaiproject.org/) that fall into an innovative or transformative category. In an email circulated to staff in her department, one Professor wrote:

Our Centre for Educational Technology (CET) colleagues, the two Cheryls, have won an international award for their online/hybrid Advanced Research Design course. This is an excellent achievement. And I think it's also a very good basis for those of us who want to move into blended mode for some of our courses (me, definitely) to learn from and build on. (Email dated: April 17, 2013, 05:42 p.m.)

We infer from this typical example that while the early majority might quickly learn and build on such innovative practices, the late adopters may require more than mere awareness but conditions and necessary support, without which such uptake would be relatively slow. Our view is that innovative practices, such as the one illustrated, 
risks being confined and remain unknown if not communicated, hence the critical role of both the communication channels and opinion leaders. However, these efforts need to be complemented with formal leadership who need to create conditions in which innovations could take place.

\section{Methodology}

We draw on data from a national research project on the use of emerging technologies by educators in HEIs in South Africa and the extent to which use of such technologies improved the qualitative educational outcomes. The research in this project was conducted between 2011 and 2013 and investigated the conditions under which South African academics' use of emerging technologies transformed educational practices.

In identifying the survey participants, convenience sampling was used, where members of the research team named possible educators who were known to be using emerging technologies in their teaching and support staff involved in supporting these technologies. This method was supplemented by a snowballing approach, which ensured that we reduced the possibility of missing innovators who could have been known within specific contexts. Overall, a total of 259 participants responded to the survey, from all the 22 public HEIs in South Africa.

The survey tool was piloted in two phases: Phase 1 targeted members of the research team, while Phase 2 included national and international academics knowledgeable in the field of emerging technologies. The pilot was aimed at ensuring that the survey questions were well designed to elicit data, which would address the research questions.

The final survey tool comprised 30 questions, which were a mixture of open- and closed-ended questions. The questions explored usage of emerging technologies, innovative practices with these technologies, the reasons for use, the effects on teaching and learning, and the constraints and support from the institution.

The survey tool provided links to further information on the various technologies listed in the questionnaire in case educators were not familiar with the ones listed in the question. Respondents had an opportunity to mention other technologies they considered emerging.

\section{Data analysis}

The 259 respondents were distributed according to their ranks as depicted in Table 1. Our assumption was that most professorial-ranked respondents had influence in the decision-making processes of institutions and therefore represented a pool of opinion leaders. We also assumed that most lecturers and non-academics were innovators or practitioners at the core of innovative uses of emerging technologies. 


\begin{tabular}{lcr}
\hline Rank & Frequency & $\%$ age \\
\hline Professors (including associates) & 40 & 15 \\
Lecturers (from senior to junior) & 167 & 65 \\
Non-academics & 52 & 20 \\
Total & 259 & 100 \\
\hline
\end{tabular}

One of the survey questions solicited descriptive comments on the participants' experience with regard to support they received for their innovative uses of emerging technologies (eg, from institutional structures, colleagues). We summarise some of their comments as follows: "A few colleagues would use this technology and not everyone is aware of how useful this tool can be..." (r1).

The above comment suggests a need for advocacy to ensure there is a greater awareness of the practice, hence improves chances of institutionalisation. Other comments allude to a general awareness of the state of the institutions regarding the adoption of emerging practices as the following remark indicates: "As part of the planning of the whole institution, I would say we are a bit behind on the use of technology to enhance learning" (r2).

It can be deduced from the above comment that institutions had opinion leaders whose general awareness and knowledge would lead to passionate advocacy of the innovative practices. Another comment that supports this view was "Certain colleagues, including the head of department (HOD), are very interested in the innovation" (r3).

The above comment clarifies that the innovators and opinion leaders need not necessarily be the same people. It should also be mentioned that most HODs are professors whose opinions are often highly respected, hence influential.

However, this kind of support from management was not a general experience of respondents as this remark suggests: "Not much at all. They close Facebook periodically on campus, we cannot download video clips and movies, IT support is non-existent ... they do not like the idea at all!!” (r4).

It can be inferred from the above comment that innovators exploring use of social media to transform practice are frustrated by institutional norms that do not align with emerging practices. We observe that while there was no formal information technology support at the said institution, there were informal support groups; hence, there is a need to leverage these informal leaders and legitimatise their practices. Some respondents confirm that innovators and early adopters are usually few and isolated: "Sometimes lonely ... I am still the only lecturer at our university delivery site to offer subjects on e-learning format to students" ( $\left.\mathrm{r}_{5}\right)$.

\section{https://repository.uwc.ac.za/}


This suggests a need to rethink the type of leadership that would identify, recognise and draw from seclusion and lone practices to bring them into institutional prominence, formulate new policies to support and encourage uptake of innovations.

Other respondents valued the support they received from their institutions, even when such support was limited to leadership giving moral support: "Good support and well informed. They enjoy having lecturers who are interested in using ICTs" (r6).

We infer from the above statement that formal leadership could exploit these interests in innovative practices to serve as gateways to changing institutional norms. We now canalyse some of the quantitative data.

Table 2: Technology used in the most innovative teaching intervention over the last 5 years

\begin{tabular}{lcr}
\hline Technology & Frequency & \% age \\
\hline LMS/CMS & 59 & 25 \\
Blogging & 20 & 8 \\
Podcasting/vodcasting & 20 & 8 \\
Social media & 18 & 8 \\
Social networking & 16 & 7 \\
Multimedia production; digital stories & 13 & 6 \\
Screencasting & 12 & 5 \\
Research databases & 9 & 4 \\
Instant messaging & 7 & 3 \\
Microblogging & 7 & 3 \\
Modelling / simulation tools & 7 & 3 \\
Web-based documents & 8 & 3 \\
Wikis & 8 & 3 \\
Bibliographic management & 5 & 2 \\
Open educational resources repositories & 6 & 2 \\
Student/personal response systems & 5 & 2 \\
Tablet computers & 6 & 2 \\
Concept and mindmapping & 3 & 1 \\
e-Books & 2 & 1 \\
Electronic portfolios & 2 & 1 \\
Internet phone & 3 & 1 \\
Social bookmarking & 2 & 1 \\
Webconferencing & 3 & 1 \\
Total & 241 & 100 \\
\hline
\end{tabular}

CMS, content management systems; LMS, learning management systems. 
The results show pockets of innovative practices (see Table 2) that still need to be diffused in HEIs. These practices tend to be limited in scope, and wide-scale institutionalisation of these practices remains peripheral.

In order to uncover the agency for these practices, Table 3 shows the motivations that underpin the uses of emerging technologies to improve students' learning experience. Personal interest (passion) ranked top (suggesting an affinity for transformative leadership) on the list and incentive (funding, policy) was the least ranked (suggesting that transactional leadership could be less effective). Availability of technologies at an institution and the role of colleagues and students as change agents were also cited as important stimuli for exploring the technologies used. We can deduce from this that among other factors, informal leaders are instrumental in influencing the decisions around the adoption of emerging technologies.

In Table 4, constraints for adoption of emerging technologies are outlined, and it can be seen that inadequate access to the Internet (21\%) was ranked as a foremost factor, seconded by the lack of computers (15\%). These constraints have led most academics and students to purchase data bundles using third-generation/Exchange Data Global system for mobile Evolution, etc. and to bring their own devices (notebooks and other handheld devices) in order to engage in innovative practices. These constraints limit institution-wide adoption of emerging practices. It can be inferred from this that given that opinion leaders would have first-hand experience of these constraints, they would be well placed to lobby formal leadership for resources and mobilise innovators to devise concerted initiatives to address these challenges. Thus, the constraints reported in Table 4 suggest a need for a dispersed rather than heroic leadership style, with senior management collaborating with opinion leaders to create conditions in which emerging practices could be adopted institution-wide.

Table 3: What prompted you to explore the use of this specific technology/ies? (175 responses)

\begin{tabular}{lrr}
\hline Motivation & Frequency & \% age \\
\hline Personal interest: I am passionate about technology & 100 & 28 \\
It is available at my institution & 81 & 23 \\
Institutional workshop/demonstration & 36 & 10 \\
My institution requires this of me & 29 & 8 \\
My colleagues had positive results using this technology & 29 & 8 \\
My students demanded this & 17 & 5 \\
I experienced it as a student in my studies & 13 & 4 \\
Other: to improve learning & 12 & 3 \\
I saw this at a conference & 11 & 3 \\
I read about it in a paper & 11 & 3 \\
Incentive (funding, policy) & 6 & 2 \\
Other (various) & 6 & 2 \\
Total & 351 & 100 \\
\hline
\end{tabular}




\begin{tabular}{lcr}
\hline Type of institutional constraint & Frequency & $\%$ age \\
\hline Inadequate access to the Internet & 20 & 38 \\
Lack of equipment (computers) & 15 & 29 \\
Institutional systems & 9 & 17 \\
Using own equipment & 5 & 10 \\
Lack of funding & 3 & 6 \\
Total & 52 & 100 \\
\hline
\end{tabular}

Table 5: Participant's constraints

\begin{tabular}{lrr}
\hline Identified constraint for participant & Frequency & $\%$ age \\
\hline Lack of colleagues' support due to fear of change, resistance & 10 & 42 \\
Lack of time/time management & 8 & 34 \\
Lack of support for students/large classes & 2 & 8 \\
Lecturer's skills and attitude & 2 & 8 \\
Difficulties in evaluating technology & 1 & 4 \\
Time management, expectation of immediate feedback & 1 & 4 \\
Total & 24 & 100 \\
\hline
\end{tabular}

The analysis of participants' constraints is listed in Table 5. It can seen from the list that "lack of colleagues' support due to fear of change, resistance" was highly ranked, and both "difficulties in evaluating technology" and "time management, expectation of immediate feedback" being the least of concerns. We infer from Table 5 that participants valued support from peers, which suggests the possible influence of informal leadership. We draw from this table that a post-heroic leadership style would be appropriate, as this would empower educators and support them as they take unexplored pathways, peer-driven professional development that is located in their respective disciplines.

It can be inferred from the analysis of Tables 1, 2, 3 and 4 that the roles of opinion leaders and change agents are dominant for successful and sustainable diffusion of innovations (see Table 1) into institutional social practices. However, as Vogel (2010) has indicated, these opinion leaders and change agents would need the assistance of senior management as formal leaders to broaden these pockets of innovation. 


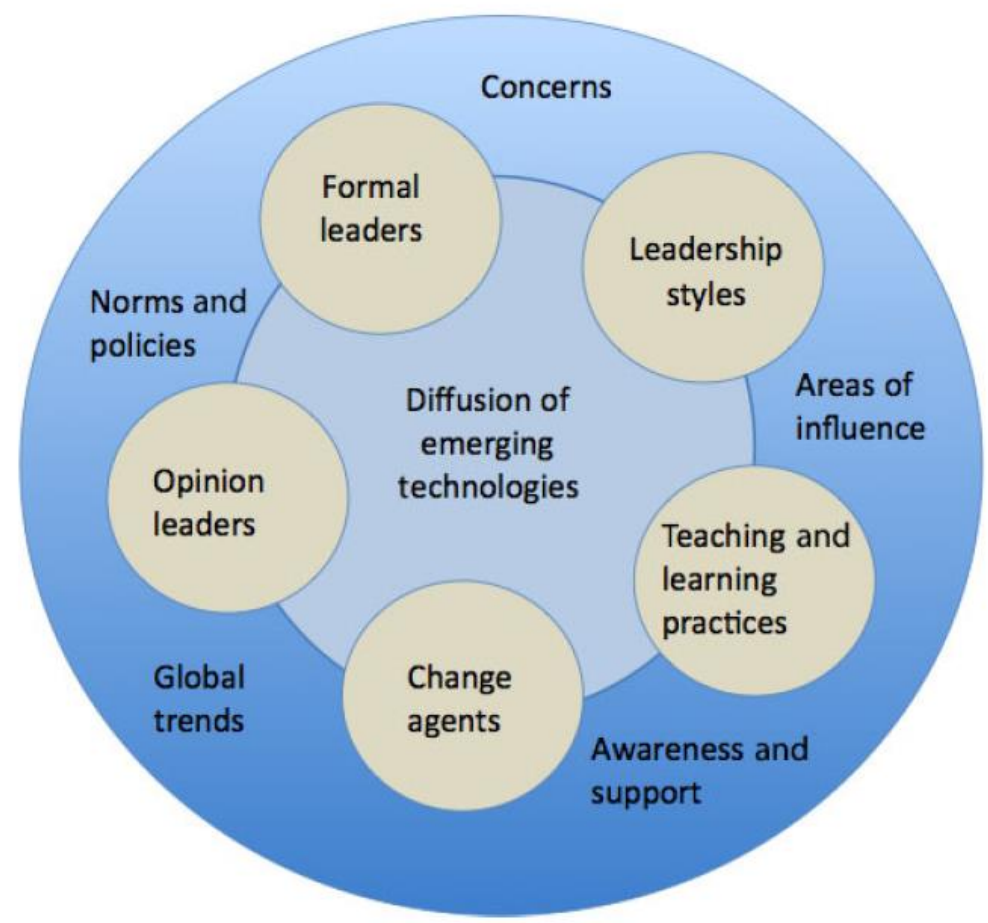

Figure 1: A wheel model for accelerating the diffusion of emerging technologies in higher education

\section{Recommendation}

We propose a model that places teaching and learning practices, change agents, opinion leaders, formal leaders and their leadership styles on the same wheel (see Figure 1). The wheel signifies progression of diffusion over time from innovators, early adopters, early majority and to late adopters. The practice of each component is impacted as emerging technologies diffuse in the social system. As these components transform, they require to be brought in some alignment for the wheel to turn and all the components are equally critical for emerging technologies' diffusion wheel to gain acceleration. However, the lubricants include global trends, institutional norms and policies, leadership concerns, areas of leadership influence and awareness of both internal and external innovative practices.

\section{Discussion and conclusion}

While formal leaders tend to have an internal institutional focus as their primary mandate, both change agents and opinion leaders exploit technologies external to institutions to improve institutional practices. Thus formal leaders of HEIs need to work with opinion leaders to ensure management of institutions has a heightened awareness of changes and innovations (Williams, Karousou \& Mackness, 2011, pp. 46 and 47). In other words there needs to be a top-down/ bottom-up or distributed approach for the cross-pollination of ideas to occur and emerging technologies to be perceived as relevant. These formal leaders then need to take a collaborative, participatory approach to encourage the wider diffusions of innovative pedagogical practice (Bates \& Sangrà, 2011).

The unofficial mandate of opinion leaders is to influence different strata of the institution to ensure wide uptake of emerging technologies. To the extent that opinion leaders are activists of innovative practices, formal leadership should formulate policies that empower and formally recognise the role of opinion leaders in the institutional 
transformation. Formal leaders need to be convinced and to convince others of the importance of emerging practices to enhance teaching and learning (Bates \& Sangrà, 2011). Leveraging informal leadership is necessary for embedding innovative practices in strategic policy documents, planning and resource allocation without which individual innovators will continue to remain peripheral to the main culture of the institutions (D’Andrea \& Gosling, 2005, p. 5).

One of the roles of formal institutional leadership is to actively promote innovative practices of teaching and learning with emerging technologies. This support is not limited to allocation of funds, formulation of policies, reward and recognition of innovative pedagogical practices (Bates \& Sangrà, 2011). In collaboration with opinion leaders, formal leaders should guide, facilitate and be responsive to a wide range of change agents (lecturers and students) in the institution.

Most "pockets of innovation" that need to be broadened into institutional practice for widespread adoption require collegial, as opposed to managed approaches. Informal or opinion leaders, rather than formal management, generally form part of the institutional ethos that is valued and vigorously defended by those who work within it. However, the broadening out of practice would be achievable if facilitated by both bottom-up (driven by informal leaders) and top-down (formal leadership), coupled by purposefully driven initiative for resourcing, supporting and rewarding it thus giving it the recognition that it needs (Vogel, 2010, p. 42).

Finally, an appropriate leadership style is required to foster creativity and accelerate the diffusion of emerging practices in higher education. Informal opinion leaders are a useful channel of communicating and influencing the uptake of innovative practices in higher education. Leveraging the capacity of opinion leaders should thus be a core responsibility of formal leadership.

\section{Acknowledgements}

We wish to thank the National Research Foundation (NRF) for funding this project. Many thanks to all the team members on the NRF project. The views expressed in this paper are neither of the NRF nor the NRF project, but we are indebted to both for making this paper possible. 


\section{References}

Bassendowski, L. S. \& Petrucka, P. (2013). Are 2oth-century methods of teaching applicable in the 21st century? British Journal of Educational Technology, 44, 4, $665-667$.

Bates, A. W. \& Sangrà, A. (2011). Managing technology in higher education: strategies for transforming teaching and learning. San Fransisco, CA: Jossey-Bass.

Casas, M. \& Stojanovic, L. (2013). Innovation in Ibero-American Universities. [online article]. Universities and Knowledge Society Journal (RUSC), 1O, 1, 240-253. UOC. Retrieved August 10, 2013, from http:// rusc.uoc.edu/ojs/index.php/rusc/article/view/v1on1-casas/v1on1-casas-stojanovicen

D’Andrea, V. M. \& Gosling, D. (2005). Improving teaching and learning: a whole institution approach. Maidenhead: SRHE and Open University Press.

Flumerfelt, S. \& Banachowski, M. (2011). Understanding leadership paradigms for improvement in higher education. Quality Assurance in Education, 19, 3, 224247.

Goldman, F. E. (2012). Leadership practices that encourage strategic thinking. Journal of Strategy and Management, 5, 1, 25-40.

Johnson, L. \& Adams, S. (2011). Technology outlook for UK tertiary education 2011-2016: a NMC Horizon Report regional analysis. Retrieved August 20, 2013, from http://dx.doi.org/10.7238/rusc.v10i1.1345 ISSN 1698-580X.

Johnson, L., Adams Becker, S., Cummins, M., Estrada, V., Freeman, A. \& Ludgate, H. (2013). NMC Horizon report: 2013 higher education edition. Austin, TX: The New Media Consortium.

Marshall, S. (2007). Leading and managing strategic change. In S. Marshall (Ed.), Strategic leadership of change in higher education (pp. 1-16). London and New York: Routledge.

Martin, S. J. \& Marion, R. (2005). Higher education leadership roles in knowledge processing. The Learning Organization, 12, 2, 140-151.

Ng'ambi, D. \& Bozalek, V. (2013). Editorial: emerging technologies and changing learning/teaching practices. British Journal of Educational Technology, 44, 4, $531-535$.

Randall, M. L. \& Coakley, A. L. (2007). Applying adaptive leadership to successful change initiatives in academia. Leadership \& Organization Development Journal, $28,4,325-335$.

Rogers, M. E. (2003). Diffusions of innovations (5th ed.). New York: Free Press.

Rogers, M. E. \& Scott, L. K. (1997). The diffusion of innovations model and outreach from the national network of libraries of medicine to Native American Communities. Retrieved August 10, 2013, from http://nnlm.gov/ archive/pnr/eval/rogers.html

Siewiorek, A., Gegenfurtner, A., Lainema, T., Saarinen, E. \& Lehtinen, E. (2013). The effects of computer-simulation game training on participants' opinions on leadership styles. British Journal of Educational Technology, 44, 6, 1011-1034.

Veletsianos, G. (2010). A definition of emerging technologies for education. In G. Velestianos (Ed.), Emerging technologies in distance education (pp. 1-22). Edmonton: AU Press. 
Vogel, M. (2010). Engaging academics in professional development for technologyenhanced learning. Goldsmiths: University of London. Retrieved August 10, 2013, from http://www.gold.ac.uk/media/ Engaging\%20Academics.pdf

Williams, R., Karousou, R. \& Mackness, J. (2011). Emergent learning and learning ecologies. IRRODL, 12, 39-59. Retrieved August 10, 2013, from http://www.irrodl.org/index.php/irrodl/article/view/883/1824 